\title{
Discovering Hidden Patterns in Loan Reimbursement
}

\author{
Professor Dr. Sorush Niknamian \\ Board Member of Weston A Price Foundation, Washington DC, USA \\ Email: so.niknamian@gmail.com
}

\begin{abstract}
Loans are the major resources at banks. However, in some cases the cost that they incur to banks soar and finally makes them detrimental, as a result of irregular or delaying reimbursement or not paying at all. Due to the low wage rates in Iranian banks and the Central Bank of Iran (CBI) regulations in determining interest rates for deposits and loans, banks are becoming more and more dependent to the loans and their related profits. Therefore, banks have to look for customers with low risk for punctual payment. According to defect loan reimbursement in past years, banks have to specify severe prerequisites and limited contracts in granting loans to their customers. Contravening banking regulations and lack of consistent customers' accreditation banks are getting into heavy losses.

Evaluating situations of the granted loans in EN Bank of Iran during a six-month period, based upon the profiles and loans history and the trend of payments useful patterns are discovered; designing a practical model of loan payment in Iran, the future default or failure to regain the granted loans is predicted and sensible methods of granting loans in Iran are developed. In order to extract hidden patterns in data statistical methods and data mining tools with focus on decision tree techniques are applied.
\end{abstract}

Key Words: Data Mining, Hidden Patterns, Decision Tree, Islamic Banking, Loan, Defaulting

\section{Introduction}

The banking industry across the world has undergone tremendous changes in the way its business is conducted. With the recent implementation, greater acceptance and usage of 'electronic' banking, the capturing of transactional data has become easier and, simultaneously, the volume of such data has grown considerably. It is beyond human capability to analyze this huge amount of raw data and to effectively transform the data into useful knowledge for the organization. The enormous amount of data that banks have been collecting over the years can greatly influence the success of data mining efforts [1].

Data Mining is a process of discovering useful patterns. Data Mining in finance typically follows a set of general steps for any Data Mining task such as problem understanding, data collection and refining, building a model, model evaluation and deployment[2]; tasks, such as data enhancing techniques, predictability tests, performance improvements, and pitfalls to 
avoid, and data mining methods such as: a variety of linear and non-linear models, multi-layer neural networks, k-means and hierarchical clustering; k-nearest neighbors, decision tree analysis, regression (logistic regression; general multiple-regression), ARIMA, principal component analysis, Bayesian learning and etc. However in finance, expert-based learning systems respond slowly to the market changes. Therefore, a technique for efficiently mining to discovering regularities from an expert's perspective has been offered. Besides, such techniques need to be integrated into the financial Data Mining loop [3].

By using data mining to analyze patterns and trends, bank executives can predict, with higher accuracy, how customers will react to adjustments in interest rates; which customers will be likely to accept new product offers; which customers will be at a higher risk for defaulting on a loan, and how to make more profitable business only through recognition customers' behavior. The banking industry is widely emphasizing to the importance of information about customers. Undoubtedly, it is consists of the whole customers' information from the richest to poorest ones, covering demographics information, transactional data, credit cards usage patterns, and etc. As a result, banks can adequately use data mining tools to identify their most profitable credit customers or high-risk loan applicants. There is, therefore, a need to build an analytical capability to address the above-stated issues and data mining attempts to provide desired answers [4]

In Iranian banking system, due to low wage rate, majority of banks income is made by loans. In this study, the researcher intends to use the CRISP-DM 6-step cycle of improvement procedure to identify the influential factors causing default discrimination control in the reviewing process. Furthermore, apply rules of decision tree with use of CART ALGORITM, to discovering hidden patterns that cause bad debt results from credit expansion, and hopefully, to establishing a set of relevant rules that can effectively eliminate those errors.

\subsection{Islamic Banking}

Islamic banking is introduced briefly in this section, since loan reimbursement in the Islamic Republic of Iran is the subject of this study. The asset and liability sides of Islamic banks have unique risk characteristics. The Islamic banking model has evolved to one-tier muzaraba with multiple investment tools. On the liability side of Islamic banks, saving and investment deposits take the form of profit sharing investment accounts. Investment accounts can be further classified as restricted and unrestricted, the former having restrictions on withdrawals before maturity date. Demand deposits or checking/current accounts in Islamic banks take the nature of qard hasan (interest-free loans) that are returned fully on demand. On the asset side, banks use \murabaha (cost-plus or mark-up sale), installment sale (medium/long-term murabaha), jo'aalah (unilateral contract), and ijara (leasing) and profit-sharing modes of financing musharaka (joint-venture agreement) and muzaraba(acting partner). These instruments on the asset side, using the profit-sharing principle to reward depositors, are a unique feature of Islamic banks. Such instruments change the nature of risks that Islamic banks face[5].

The whole loans' contracts can be categorized in two broad types: 
The traditional contracts offered by Islamic banks which are divided into fixed return (murabaha, qard hasan, ijira, jo'aalah and so on) and, variable return methods (muzaraba and musharaka). The customers' debt repayment Consist of three parts:

Maturity: Past due receivables for 2 to 6 months.

Pending Quest: past due receivables for 6 to 18 months

Doubtful Account: Past due receivables for more than 18 months.

\section{Research methodology}

\subsection{CRISP methodology}

There are different methodologies for implementing a data mining model that describes commonly used approaches by which expert data miners use to tackle problems. One of the frequent and well-known methods is CRISP. CRISP uses six phases to describe the process from gathering business requirements to deploying the results [6].

\section{Stage1: Business Understanding}

In this stage, a clear understanding of the project's goal and appropriate plan and device is needed. The scope of this study is banking business in Iran. The bank's main income derived from the granting loans. Consequently, loan repayment behavior affects the benefit and cost of banks tremendously. Data of the study were collected from the loan contracts at EN-bank as the first private bank in Iran. According to this database a sum of 117000 loans' documents were granted from April 2010 to September 2010 - were investigated.

\section{Stage2: Data Understanding}

In this phase, preliminary data were collected through banking systems, and then data review was done. Finally, the most suitable fields were selected. The target and inputs variables are defined as shown in table 1 .

Table 1: Description of input and output variables

\begin{tabular}{|l|l|c|c|}
\hline Variable & Description & $\begin{array}{c}\text { Target/ } \\
\text { Input }\end{array}$ & Type \\
\hline Region & $\begin{array}{l}\text { Geographic area of lender branch which includes } \\
\text { Capital, Metropolitan and Town }\end{array}$ & Input & Set \\
\hline
\end{tabular}




\begin{tabular}{|l|l|c|c|}
\hline Type Loan & $\begin{array}{l}\text { Types of loan in Islamic banking which Was defined } \\
\text { in the previous section }\end{array}$ & Input \\
\hline Loan Value & $\begin{array}{l}\text { Loan amount which was given to the customer (IRR } \\
\text { rate) }\end{array}$ & Input & Range \\
\hline $\begin{array}{l}\text { Current } \\
\text { Status }\end{array}$ & $\begin{array}{l}\text { Include five status : To Be Settled, Active, Maturity, } \\
\text { Pending Quest, Doubtful Account }\end{array}$ & Target & Order Set \\
\hline $\begin{array}{l}\text { Approving } \\
\text { Reference }\end{array}$ & $\begin{array}{l}\text { There are three categories: Branches, Central } \\
\text { Committee, Board Of Directors } \\
\text { Type }\end{array}$ & Include two type: Individual and Institutional & Input \\
\hline
\end{tabular}

We choose "Current Status" as target variable which depends on the time delay in payment installment. This variable was categorized to five classes based on increasing in risk and cost of the granted loans.

\section{Stage3: Data preparing}

This phase is one of the most important and often time-consuming aspects of data mining projects. Reconstructing, cleaning and preparing data in this stage; the relevant subsets of data are advanced, and a table of suitable fields of aggregated data is produced. Aggregation in this study means that the new values are computed by summarizing information from multiple tables.

\section{Stage 4.Modeling}

There are numerous techniques available for each type of data mining model. Choosing data mining techniques should be based on the data characteristics and business requirements [7]. One of the most popular classification techniques used in the data mining process is represented by decision trees, because after accomplishing a classification process, a decision is individually made [8].

Using current and past status of loans profiles and discovered rules, we predict the reimbursement behavior in the future. Understanding problem to achieve a series of decision rules for predicting and assigning to the high and low- risk categories of loans, we apply decision trees method. One of the most advantages of decision tree is the high compatibility of the business logic and decision tree method in this respect. Besides, decision tree based on relatively simple model and its production is very fast. Unlike statistical methods, this method requires no assumptions about the distribution or attributes independence. However, analysts should be causations in selecting the correct methodology for successful data mining process.

Decision trees In case of numeric attributes, can be geometrically interpreted as a of hyperplanes, each orthogonal to one of the axes. Individually, decision-makers

collection prefer less 
complex decision trees, since they may be considered more comprehensible. The tree complexity has a crucial effect on its accuracy. The tree complexity is explicitly controlled by the stopping criteria used and the pruning method employed. Decision tree induction is closely related to rule induction. Each path from the root of a decision tree to one of its leaves can be transformed into a rule simply by conjoining the tests along the path to form the antecedent part, and taking the leaf's class prediction as the class value. The resulting rule set can then be simplified to improve its comprehensibility to a human user, and possibly its accuracy [10].

CART algorithm used in this study, due to less error in prediction, and the high percentage of data that are correctly classified. CART stands for Classification and Regression Trees. It is characterized by the fact that it constructs binary trees, namely each internal node has exactly two outgoing edges. The splits are selected using the towing criteria and the obtained tree is pruned by cost-complexity Pruning. When provided, CART can consider misclassification costs in the tree induction. It also enables users to provide prior probability distribution. An important feature of CART is its ability to generate regression trees. Regression trees are trees where their leaves predict a real number and not a class. In case of regression, CART looks for splits that minimize the prediction squared error (the least-squared deviation). The prediction in each leaf is based on the weighted mean for node.

In this study, considering the number of installment field, data was divided into two parts and their rules separately investigated. The variables were divided into two groups: input variables and target variable. The target variable is predicted by input variables. Following two states with rules that have been extracted from the CART algorithm considered.

\section{1) Number of Installments $=1$}

- IF Type Loan= 'Musharaka' AND Loan Value $<2,800,000,000$ ' AND

Region=' Metropolitan ' THEN Current Status=' To Be Settled'

- IF Type Loan= 'Musharaka' AND Costumer Type=' Individual' AND Region=' Town ' AND Loan Value > '1,300,000,000' AND Loan Value <'1,800,000,000' THEN Current Status=' Active '

- IF Type Loan= 'Musharaka' AND Costumer Type=' Individual' AND Region=' Town ' AND Loan Value > '1,200,000,000' AND Loan Value < '1,300,000,000' THEN Current Status=' Maturity '

- IF Type Loan= 'Musharaka' AND Costumer Type=' Individual' AND Region=' Town' AND Loan Value < '1,200,000,000' THEN Current Status=' Pending Quest '

- IF Type Loan= 'Muzaraba' AND Region=' Town ' AND

Loan Value < '1,900,000,000' THEN Current Status=' Doubtful Account' 


\section{2) Number of Installments $>=1$}

- IF Loan Value > '15,097,500' AND Type Loan= ' Jo'aalah ' AND Approving Reference='Central Committee' THEN Current Status=' To Be Settled'

- IF Loan Value <'52,000,000' AND Type Loan= 'Murabaha' AND Approving Reference='Central Committee' THEN Current Status=' Active'

- IF Loan Value < '60,000,000' AND Region=' Metropolitan' AND Type Loan= 'Jo'aalah ' THEN Current Status=' Maturity'

- IF Loan Value < '54,300,000' AND Region=' Capital ' AND Type Loan= ' Musharaka ' THEN Current Status=' Pending Quest'

- IF Loan Value > '120,000,000' AND Type Loan='Muzaraba' AND Costumer Type=' Individual' AND Approving Reference='Branch'

THEN Current Status=' Doubtful Account'

\section{Stage5. Evaluation}

After establishing the effectiveness of a decision tree should be measured for this, the train data is used. The indicator is measured in this section is: Percentage of data that are correctly classified and the predicted class, real class, they are equally. In this study, Percentage of data that are correctly classified is more than $85 \%$.

\section{CONCLUSION}

In this study, we investigated on granted loans data in a private bank in Iran. CART decision tree as a classification technique is used to discover hidden pattern between input variables - such as loan type, loan value, region of branches, customer type and etc - and target variable - "current status" which can be Settled, Active, Maturity, Pending Quest, and Doubtful Account. The result of this study is the rule set which can be useful for predicting the current status of each loan profile and the bank can make effectiveness decision in granting loan in future.

\section{References}

[1].Hian, C. K. \& Gerald, T. (2005), 'Data Mining Applications in Healthcare' Journal of Healthcare Information Management 19(2): 64-65. 
[2].Klosgen, W. \& J. Zytkow (2002), Handbook of Data Mining and knowledge discovery, Oxford Univ.

[3].Kavalerchuk, B. \& E. Vityaev(2010), Data Mining and Knowledge Discovery Handbook, springer.

[4]. Bhasin, Madana lal (2006), Data Mining:A Competitive Tool in the Banking and Retail Industries.' Banking and Finance'

[5]. Kabir Hassan, M (2007). Handbook of Islamic Banking, Edward Elgar

[6].Larose, D.T. (2006), "Data mining methods and models", John Wiley \& Sons, Inc., Hoboken, New Jersey

[7]. E.W.T. Ngai , Li Xiu, D.C.K. Chau (2009), Application of data mining techniques in customer relationship management: A literature review and classification, Expert Systems with Applications 36 -2592-2602

[8]. Gorunescu, F. (2011), Data Mining Concepts, Models and Techniques,Springer

[9].Dobbertin, Matthias; Biging, Gregory S.(1998), Using the Non-Parametric Classifier CART to Model Forest Tree Mortality, Society of American Foresters, Volume 44, Number 4, pp. 507-516(10)

[10].Quinlan, J.R. (1987), International Journal of Man-Machine Studies, Elsevier, Volume 27, Issue 3, Pages 221-234 